\title{
(2) (1) \\ ENTRE RELIGIÃO E POLÍTICA: DIVERGÊNCIAS NA RECEPÇÃO OCIDENTAL DE MIKHAIL BAKHTIN
}

\author{
Between Religion And Politics: Divergences In Mikhail Bakhtin’s Ocidental Recepcion
}

\author{
Daniel Jaccoud Ribeiro de Souza \\ Psicólogo. Mestrando em psicologia \\ pela Universidade Federal do Paraná
}

RESUMO: A leitura do russo Mikhail Bakhtin, nos países ocidentais, está atravessada pela diversidade em focos institucionais, marcados fundamentalmente por uma visão religiosa, de um lado, e por uma visão política, de outro. Dentre diversos estudiosos mundiais desse pensador, observa-se que a primeira visão encontrou guarida especialmente nos Estados Unidos da América, enquanto a segunda vem sendo defendida no Brasil. Tal diversidade está ligada à sua larga produção teórica sobre diferentes temas do conhecimento humano, dentre os quais tradicionalmente destacam-se suas contribuições à crítica literária, à linguística e à filosofia da linguagem. Analisando-se especificamente as diferenças de sua leitura entre os Estados Unidos e o Brasil, nota-se que a produção acadêmica sobre sua teoria começou a desenvolverse com profundidade na década de 1980. A pesquisa mostrou que, na interpretação estadunidense vinculada à Yale University, Bakhtin é visto como um pensador cristão, que a despeito dos expurgos e da censura soviética, logrou traduzir em termos de uma filosofia da linguagem seu pensamento teológico pautado em uma visão não institucional do cristianismo ortodoxo oriental; enquanto no âmbito brasileiro da Universidade Federal do Paraná nota-se um Bakhtin fundamentalmente materialista, cujos conceitos partem das análises dialéticas. O objetivo deste estudo consistiu, portanto, na discussão acerca da recepção institucional das teorias de Mikhail Bakhtin no Ocidente.

Palavras-chave: Mikhail Bakhtin; Recepção ocidental; Institucionalidades; Política; Religião.

ABSTRACT: The reading of the Russian Mikhail Bakhtin, in the occidental countries, is crossed by the institutional focus diversity, fundamentally marked by a religious view, in one side, and by a politic view, in another. Between diverse world scholars of this thinker, it's observable that the first view finds guard specially in the United States of America, while the second is going to be defended in Brazil. Such diversity is connected to its large theoretical production about different human knowledge themes, among which traditionally is highlighted his contributions to the literary criticism, to the linguistic and to the language philosophy. Especially when analyzing the differences in the reading between United States and Brazil, it shall be noticed that the academic production about his theory begins to be deeply developed in 1980's decade. The research shows that in the American interpretation of Yale University, Bakhtin is seen as a Christian thinker that, despite the Soviets' purges and censorship, managed to translate his theological thinking based on a non-institutional Oriental Orthodox Christian view into a philosophy of the language; while in the Brazilian Universidade Federal do Paraná, it is possible to note a Bakhtin deeply materialist, whose concepts initiate from the dialectical analysis. The objective of this study consists in, therefore, the discussion about Mikhail Bakhtin theories' institutional reception in the Occident.

Keywords: Mikhail Bakhtin; Occidental reception; Institutions; Politics; Religion. 


\section{Introdução}

Os estudos ocidentais sobre o russo Mikhail Bakhtin vêm crescendo constantemente nos últimos anos. Embora sua inserção na Europa e nas Américas tenha sido tardia, tal fenômeno vem ocorrendo com consistência e continuidade. Não obstante, as leituras realizadas têm se mostrado diferentes e, em algumas situações, mesmo contraditórias. Embora tal pluralidade de interpretações possa ser muito bem esclarecida por meio da própria teoria bakhtiniana, este fenômeno não deixa de ser notável e intrigante.

A recepção de Bakhtin no Ocidente foi permeada por diversas variáveis e esteve sujeita às adaptações quanto ao espaço e ao tempo de produção e de leitura das obras. As diversas facetas desta conjuntura levaram à observação de diferentes Mikhail Bakhtin. Um teólogo, um cientista da religião, um filósofo existencialista, um teórico político, um linguista, um crítico literário. A definição sobre quem foi Bakhtin repousa sobre o confronto intelectual de seus comentadores.

Não sendo possível, no curto espaço de que se dispõe, revelar a completude das vicissitudes que envolvem a leitura ocidental do russo, o objetivo deste artigo consiste em traçar as diferentes visões entre dois importantes grupos de leitura bakhtiniana, nomeadamente, as recepções realizadas pela Yale University (YU) e pela Universidade Federal do Paraná (UFPR).

No presente estudo, a Yale University é tomada a partir de Katarina Clark e de Michael Holquist, docentes filiados a esta instituição e com trabalhos e atuação na área de literatura e linguagem eslavas. Clark e Holquist tornaram-se mundialmente conhecidos no âmbito dos estudos bakhtinianos em virtude da publicação conjunta da obra Mikhail Bakhtin, que consiste na mais completa biografia do teórico, publicada após vários anos de estudo e viagens realizada a então União Soviética. Tal trabalho tornou-se referência obrigatória aos comentadores de Mikhail Bakhtin, de forma que todos os principais estudiosos brasileiros já apresentaram menções ou mesmo resenhas sobre a obra (por exemplo, Faraco ${ }^{1}, \mathrm{Tezza}^{2}$, Bezerra $^{3}$, Schnaiderman $^{4}$, Brait $^{5}$, Amorim $^{6}$,

\footnotetext{
${ }^{1}$ Faraco, Carlos Alberto. Linguagem \& diálogo: as ideias linguísticas do Círculo de Bakhtin. São Paulo: Parábola Editorial, 2009.

${ }^{2}$ Tezza, Cristovão. A vida polifônica de Mikhail Bakhtin, de Katerina Clark e Michael Holquist, 1998. Disponível em: 
dentre outros).

Já no âmbito sul-americano, Cristovão Tezza esclarece que o núcleo de estudos em Mikhail Bakhtin na Universidade Federal do Paraná foi inicialmente estabelecido e coordenado por Carlos Alberto Faraco, hoje professor aposentado do departamento de Letras desta universidade. Segundo Tezza ${ }^{7}$, Faraco foi o responsável por introduzir Bakhtin no Paraná, ao longo da década de 1980. Desde então, diversos trabalhos foram publicados sob a chancela de Faraco e de seus colegas.

Para que se torne possível compreender, mesmo que minimamente, a problemática envolvida na recepção plural do pensamento de Bakhtin - o que é visível na diversidade de tratamento realizado pela YU e pela UFPR - deve-se analisar o desenvolvimento da vida e da carreira do pensador russo. Quando não evidenciado contrariamente, as referências biográficas a seguir seguirão o indicado por Clark e Holquist ${ }^{8}$.

Nascido no ano de 1895, na cidade de Orel, ao sul de Moscou, Mikhail Mikhailóvitch Bakhtin descendia de família da nobreza russa. Durante sua infância, sua família mudou-se para diferentes cidades e Bakhtin vivenciou os traços culturais de Vilno, na Lituânia, e de Odessa, na Ucrânia, antes de rumar para São Petersburgo. Se Vilno marcou o infante com sua cultura múltipla e com a interconexão de diferentes povos, religiões, costumes e idiomas, Odessa o marcou com o aprofundamento acadêmico, sendo que nesta cidade Bakhtin foi primeiramente apresentado às teorias de Martin Buber e de Sören Kierkegaard. É digno de nota que, aos dezesseis anos de vida, pouco após sua chegada à Ucrânia, Bakhtin manifestou o quadro de osteomielite, doença que o acompanharia por toda a vida e que seria responsável por diversas limitações sofridas.

Após a chegada à vida adulta, não manteve contato frequente com seus familiares, indicando que sua maior perda consistiu no afastamento de seu irmão mais

em:

<http://www1.folha.uol.com.br/fsp/resenha/

rs13089814.htm>. Acesso em: 9/11/2013.

${ }^{4}$ Schnaiderman, Boris. Bakhtin e o Ocidente: etapas de uma aproximação. In.: Clark, Katerina; Holquist, Michael. Mikhail Bakhtin. São Paulo: Perspectiva, 2008.

${ }^{5}$ Brait, Beth. Bakhtin e a natureza constitutivamente dialógica da linguagem. In.: Brait, Beth (Org.). Bakhtin, dialogismo e construção de sentido. 2. ed. rev. Campinas: Unicamp, 2005.

${ }^{6}$ Amorim, Marilia. Para uma filosofia do ato: "válido e inserido no contexto". In.: Brait, Beth (Org.). Bakhtin, dialogismo e polifonia. São Paulo: Contexto, 2012.

${ }^{7}$ Tezza, Cristovão. A construção das vozes no romance. In.: Brait, Beth (Org.). Bakhtin: dialogismo e construção de sentido. 2. ed. rev. Campinas: Unicamp, 2005.

${ }^{8}$ Clark, Katerina; Holquist, Michael. Mikhail Bakhtin. São Paulo: Perspectiva, 2008. 
velho, Nikolai, durante a guerra civil que se seguiu às revoluções de 1917. Sabe-se que após Nikolai abandonar o país, Bakhtin nunca mais reencontrou o irmão.

Durante a Revolução Russa, o jovem Bakhtin contava com cerca de 23 anos e, embora não tenha participado ativamente dos levantes, foi imerso na onda de discussões teóricas que se seguiu ao movimento. Nessa época, formou-se em filologia e história pela Universidade de São Petersburgo. Clark e Holquist ${ }^{9}$ enfatizam que sua formação acadêmica consistiu em período no qual entrou em contato com os mais diversos grupos literários, políticos, artísticos e religiosos, frisando que o apego pela última categoria superou em muito a aproximação para com todas as demais.

Na sequência da Primeira Guerra Mundial e da Revolução, a Rússia passou a sofrer com graves dificuldades de estrutura e abastecimento, sendo frequentes os problemas nas maiores cidades. Diante das dificuldades existenciais na antiga São Petersburgo, já nomeada Petrogrado, Bakhtin buscou condições de vida mais cômodas em cidades menores, no que é precedido e acompanhado por inúmeros contemporâneos. Neste movimento, chega à cidade de Nevel em 1918.

Nessa cidade, formou-se um grupo de pensadores, em sua maioria jovens, cujo objetivo comum consistia na investigação dos mais diversos campos do saber humano, e cuja ênfase era o debate de ideias entre seus membros. Através das chamadas noites filosóficas, os participantes promoviam discussões sobre obras clássicas ou contemporâneas, instigando a reflexão mútua. O grupo, que futuramente ficou conhecido como Círculo de Bakhtin em virtude da propagação do pensamento deste sobre os demais membros, era multidisciplinar, por assim dizer. Em sua primeira versão, estiveram presentes figuras como Vladimir Ruguévitch, engenheiro polonês, Valentin Volochinov, estudioso do direito e da música, Lev Pumpiânski, estudioso de filosofia e literatura, Maria Iudina, pianista, Matvei Kagan, já doutor em filosofia e com campo de atuação em matemática, e o próprio Bakhtin, além de outros participantes com menor visibilidade.

Clark e Holquist ${ }^{10}$ esclarecem que o contexto russo pós-revolucionário foi marcado pela ascensão da geração jovem em decorrência da lacuna aberta pela emigração ou silenciamento da geração mais antiga e intelectualmente influente. Para os jovens russos, estava posta a oportunidade de divulgação de suas ideias, o que ocorreu 
especialmente em focos descentralizados e independentes dos pólos nacionais. Essa busca pelas cidades provincianas da Rússia, em parte motivada pela busca de melhores suprimentos e em parte pela fuga do controle bolchevique sobre a produção intelectual, mobilizou produtivos encontros em diversas cidades do país. "Nesta existência inquieta, errante, surgiram breves interlúdios em cidades provincianas, uma após outra, quando espíritos apurados se reuniram por acaso. Seu encontro desencadeava brilhantes, mesmo que efêmeros, intercâmbios intelectuais, acompanhados talvez pela fundação de alguma sociedade ou revista." 11

O grupo de Nevel reunia-se com frequência e passou a nortear o cotidiano cultural da cidade, especialmente com a realização de debates públicos que, para Clark e Holquist $^{12}$, não raro retomavam a temática religiosa, sobre a qual Bakhtin teria tomado parte.

Embora a ida de Bakhtin para Nevel the tenha sido benéfica, material e intelectualmente, os primeiros anos após a Revolução lhe foram árduos, tanto do ponto de vista financeiro quanto da propagação de suas ideias. A despeito de motivos secundários para tais dificuldades, há certo consenso entre seus comentadores ao declararem que as ideias vanguardistas de Bakhtin estavam em claro descompasso com sua época (Clark, Holquist ${ }^{13}$, Faraco ${ }^{14}$, Schnaiderman $^{15}$ ).

O Círculo permaneceu por pouco tempo em Nevel. Atraídos por maiores possibilidades de desenvolvimento de seus estudos, os participantes começaram a rumar para a cidade de Vitebsk, local onde Pumpiânski passou a residir, formando uma instituição para estudos kantianos em 1919. Bakhtin mudou-se para Vitebsk no ano seguinte, paralelamente a outros membros de seu grupo, que encerrou suas atividades em Nevel em 1921. Bem entendido, houve fragmentação e nem todos os componentes rumaram para o mesmo lugar. Clark e Holquist ${ }^{16}$ pontuam que Kagan e Iudina seguiram suas carreiras em outras cidades e, eventualmente, encontravam-se com o restante do grupo agora estabelecido em Vitebsk.

Vitebsk era cidade com maiores alternativas culturais do que Nevel e,

\footnotetext{
${ }^{11} I d .$, p. 64.

${ }^{12}$ Id., Passim.

${ }^{13} I d$.

${ }^{14}$ Faraco, C. A. Op. cit.

${ }^{15}$ Schnaiderman, Boris. Bakhtin 40 graus: uma experiência brasileira. In.: Brait, Beth (Org.). Bakhtin, dialogismo e construção de sentido. 2. ed. rev. Campinas: Unicamp, 2005.

${ }^{16}$ Clark, K; Holquist, M. Op. cit.
} 
estabelecida junto a uma estrada de ferro e possuindo um porto fluvial, tinha ligações constantes com as maiores cidades da Rússia. Neste local, novos membros associaramse ao grupo que passou a contar com as figuras de Ivan Solertínski, que trabalhava para o governo no setor da educação e Pável Medvedev, jurista vinculado ao movimento soviético. Durante parte de sua permanência em Vitebsk, o Círculo gozou de apoio e financiamento do Partido Comunista, que na época incentivava as produções artísticas e os confrontos intelectuais.

Foi nesta cidade, também, que Bakhtin encontrou sua futura esposa, Elena Okolóvitch, importante auxílio frente ao desenvolvimento de seu quadro de osteomielite, que já limitava suas atividades profissionais.

Clark e Holquist ${ }^{17}$ comentam que, entre os anos de 1918 e 1924, Bakhtin trabalhou em pelo menos seis textos que, embora bastante heterogêneos, tocavam basicamente as temáticas da arte, da estética e da filosofia moral. Para esses pensadores, todos esses projetos consistiam em diferentes versões de uma mesma obra intelectual, ao qual denominam de "arquitetônica da respondibilidade". Faraco ${ }^{18}$ intitula essa mesma proposta bakhtiniana de "prima philosophia".

Estes trabalhos eram marcados pelo neokantismo e pela preocupação com a eventicidade e singularidade da existência. Nesta época Bakhtin começa a esboçar sua crítica ao que chamava de teoreticismo, ou seja, à abstração científica de sua época que, na busca por padrões e constantes, frequentemente ignorava as singularidades e particularidades. O pensador defende que a vida humana transcorre neste plano concreto e individualizado, e não naquele abstrato e genérico. Apresenta, também, sua ideia de que o ato de existir é inseparável do posicionamento axiológico, valorativo, do indivíduo frente ao seu mundo.

Dentre os textos produzidos nesse período, dois destacam-se pela sua profundidade, embora ambos inacabados. Em Para uma filosofia do ato responsável, o teórico debate o posicionamento individual da existência e questiona-se sobre as condições pelas quais um pensamento pode ser tomado como ético. Já em $O$ autor e o herói na atividade estética, tece considerações sobre a constituição subjetiva a partir da alteridade, retirando conceitos da crítica literária para discutir a relação entre o autor e seu personagem.

${ }^{17}$ Id.

${ }^{18}$ Faraco, C. A. Op. cit. 
Embora seus estudos tenham se aprofundado em Nevel e Vitebsk, nenhuma dessas cidades fornecera a Bakhtin condições concretas de crescimento profissional. Sofrendo dificuldades para publicar suas obras e sem conseguir angariar qualquer posição acadêmica, opta por sair de Vitebsk em busca de novas oportunidades, no que é acompanhado por vários de seus companheiros de investigação filosófica.

Essa mudança não foi, porém, apenas geográfica. Ao regressar a Petrogrado, agora nomeada Leningrado, vários integrantes do grupo conseguiram se estabelecer profissionalmente em cargos relacionados à academia ou à promoção da cultura. Bakhtin, entretanto, não trabalhou oficialmente e, pela crescente gravidade de seu quadro de saúde, passou a gozar de uma pensão estatal. Nesta grande cidade, sua imagem pública apagou-se nitidamente, em contraste com as provincianas Nevel ou Vitebsk. Por outro lado, foi um período de importante produção intelectual, na qual foi escrito seu relevante livro sobre Dostoievski, além das chamadas obras disputadas Marxismo e filosofia da linguagem, $O$ Freudismo e $O$ método formal nos estudos literários.

Diz-se que são obras disputadas na medida em que as duas primeiras foram publicadas sob a assinatura de Valentin Voloshinov, enquanto a última foi atribuída a Pável Medvedev, ambos seus colegas de Círculo. Estas autorias foram inquestionavelmente mantidas por mais de três décadas até que, nos anos 1960, o linguista Viatcheslav Ivanov afirmou que Mikhail Bakhtin era o verdadeiro escritor dos livros. Desde então, não há consenso na comunidade acadêmica que, basicamente, se divide em três posições principais: assumir a autoria de Bakhtin sobre os textos disputados, reconhecer a autoria enunciada por ocasião das publicações, ou conciliar ambos, indicando dupla autoria de Bakhtin e Voloshinov ou de Bakhtin e Medvedev. Enquanto Faraco ${ }^{19}$ declara que sua posição é a de respeitar a memória dos escritores, aceitando que os trabalhos foram lavrados por Voloshinov e Medvedev, Clark e Holquist $^{20}$ defendem que o único autor foi Bakhtin, e que seus discípulos apenas lhe emprestaram os respectivos nomes como fim de facilitar o árduo processo de publicação das obras.

Em todo o caso, o período foi de ampla produção intelectual, quer para Bakhtin, quer para seus colegas. A edição do Círculo em Leningrado era composta, em seu

${ }^{19} I d$.

${ }^{20}$ Clark, K.; Holquist, M. Op. cit. 
núcleo, pelos veteranos já participantes, além de novos membros que eram introduzidos, tais como Kanaiev, Konrad, Vaguinov, Frankóvski, Engelhardt e Zaliéski. Nesse contexto, Bakhtin assumia gradualmente o papel de coordenador do núcleo, embora, naturalmente, nem todos os membros concordassem com seu pensamento.

Mas a marca fundamental da permanência do grupo em Leningrado foi a chamada virada linguística ${ }^{21}$. Por volta de 1925/1926, os estudos do Círculo sofreram importantes mudanças e, afastando-se do neokantismo e do existencialismo, passaram a considerar mais frequente e profundamente a filosofia da linguagem. Doravante, todos os trabalhos de Bakhtin levarão em conta o aspecto linguístico e suas anteriores considerações éticas e existenciais serão reenunciadas por meio de novos conceitos e ângulos de visão.

Embora os anos de 1919 a 1929 tenham sido um período breve na vida de Bakhtin, e suas obras tenham alcançado pouca repercussão nesta época, sua produção é foco de debate intelectual entre os seus receptores.

Clark e Holquist ${ }^{22}$ esclarecem que havia vasta pluralidade de associações no interior da União Soviética e defendem que, ao longo desses dez anos, Bakhtin foi profundamente influenciado pela Ortodoxia Russa, especialmente através de três heterogêneos grupos religiosos: o Voskresenie, a Irmandade de São Serafim e o Cisma Josefita. Bakhtin nunca declarou participar de qualquer deles, mas conhecia vários membros, estabelecendo contato com eles através de discussões, indicando tanto pontos de concordância quanto de discordância do pensador quanto os princípios dos grupos. Acrescenta-se que alguns integrantes do Círculo eram também membros dessas sociedades religiosas.

Na leitura de Clark e Holquist, "o Cristianismo o influenciou fortemente. Mas, como sempre em seu caso, a influência foi indireta e, assim sendo, torna-se difícil medila com precisão. Seu pensamento nesta área é mais uma filosofia da religião do que uma teologia que assume a fé como um a priori." 23

Nesse sentido, os teóricos estadunidenses esclarecem que o Voskresenie (do russo, "ressurreição") era um grupo bastante variado, sendo integrado por pessoas associadas a diferentes confissões e instituições religiosas, ou mesmo a nenhuma, e que

\footnotetext{
${ }^{21}$ Faraco, C. A. Op cit.

${ }^{22}$ Clark, K.; Holquist, M. Op. cit.

${ }^{23}$ Id., p. 105.
} 
tinham como eixo central a figura de Cristo. O coletivo apresentava também um tom político favorável à Revolução e ao estabelecimento do socialismo.

Outro grupo religioso de destaque, quer por sua clandestinidade, quer por seu posicionamento político tradicional foi a Irmandade de São Serafim que, diferentemente da Voskresenie, indicava apego ao modelo político monárquico. Embora o caráter místico e conservador indiquem amplo confronto ao pensamento de Bakhtin, este fora acusado de ser integrante do grupo.

Necessário ainda mencionar o cisma josefita, iniciado em 1928, em Leningrado, como oposição ao pronunciamento do Patriarca Sergii que, no ano anterior, havia declarado a subordinação da Igreja Ortodoxa ao Estado soviético. Embora não tenha se assumido como um movimento de massa, alcançou adeptos nas principais cidades do país.

Clark e Holquist ${ }^{24}$ pontuam que sua aproximação ao cisma tornou-se ainda mais problemática por conta de sua provável atividade docente em cursos de formação pastoral organizados por Scherbov. A partir da lacuna aberta pelo fechamento do Seminário Teológico existente em Leningrado, diversos cursos independentes para preparação de sacerdotes ortodoxos surgiram, e Bakhtin teria lecionado em um deles, imbuído de uma perspectiva anti-institucional e cismática. O curso de Scherbov e seu corpo docente foram objetos de repressão em 1928.

Embora Bakhtin não tenha se vinculado diretamente a qualquer desses grupos, sua posição intelectual é interpretada por alguns de seus comentadores como relacionada às concepções dessas associações, seja no tocante à concordância ou à discordância com elas. Não só no aspecto religioso, mas também no artístico ou político, é possível ver a busca de Bakhtin por seu posicionamento singular. O teórico da autoria, do diálogo, das vozes, dos valores, do riso, da inversão hierárquica e da pluralidade nunca se confinou a um único nome ou instituição.

O palpável anticlericalismo de seu livro sobre Rabelais tornou difícil distinguir conexões entre a obra publicada de Bakhtin e sua religiosidade. Mas Bakhtin jamais foi um russo ortodoxo convencional no sentido de conformar-se a uma religião organizada. Era bem mais um intelectual religioso vindo da tradição ortodoxa. Seus pontos de vista religiosos não provinham tanto do pensamento ortodoxo tradicional no interior da Igreja como da revivescência

\footnotetext{
${ }^{24}$ Id., Passim.
} 
religiosa no começo do século $\mathrm{XX}$ entre intelectuais russos que procuravam arrotear novos terrenos no pensamento teológico. ${ }^{25}$

Baseados nessa influência, os comentadores de Yale traçam diversos paralelos: a relação entre autor e herói representa a relação entre Deus e a humanidade; a exotopia (busca pelo distanciamento para se alcançar um excedente de visão) remete à kenosis (o esvaziamento de Cristo); a riqueza e complexidade da vida cotidiana apontam para a corporeidade de Cristo; o signo (visto como elo entre o linguístico e o extralinguístico) corresponde à Palavra tornada carne. Para eles, a autoria é o fundamento da teoria de Bakhtin - uma teoria da criação, portanto - e, também, um dos conceitos em que mais se observa a influência da Ortodoxia Russa.

Se Katerina Clark e Michael Holquist veem na teoria bakhtiniana fortes e indispensáveis vínculos com a tradição cristã ortodoxa, Carlos Faraco e Cristovão Tezza veem a influência do pensamento materialista sobre a teoria bakhtiniana.

Em discordância à interpretação de Yale, a escola do Paraná deixa de lado uma possível influência religiosa e defende que Mikhail Bakhtin foi marcado pela perspectiva materialista. Contudo, não defende-se um posicionamento estritamente marxista de Bakhtin que, desde suas primeiras obras, apresentou críticas e posicionamentos divergentes ao conceitual do qual lançara mão a Revolução e a União das Repúblicas Socialistas Soviéticas. Faraco declara: "ao que tudo indica - isto é, pelo que se pode inferir dos textos assinados por ele e pelas informações biográficas de que dispomos (embora ainda bastante precárias) -, Bakhtin não vinculava seu pensamento a uma arquitetônica que se pudesse classificar de marxista." 26

Tezza, concordando com Faraco quanto à independência de Bakhtin frente à matriz marxista, acusa Clark e Holquist, entretanto, de ignorarem completamente esta relevante influência na biografia que escreveram. Embora elogie o caráter informativo da obra quanto à vida do pensador, critica-a de parcialidade ideológica. "Parece estar exatamente aqui, no eixo da interpretação do pensamento bakhtiniano, o ponto fraco da obra de Clark \& Holquist. O aspecto mais visível dessa fraqueza - em certos momentos, gritante - é a tentativa de a todo custo fazer de Bakhtin um teólogo, ou um pensador religioso." 27

\footnotetext{
${ }^{25}$ Id., p. 145.

${ }^{26}$ Faraco, C. A. Op. cit., p. 27.

${ }^{27}$ Tezza, C. A vida polifônica...
} 
É importante salientar que, para esses comentadores brasileiros, Bakhtin não é facilmente classificável. Antes, observam em seu trabalho exatamente o movimento de fuga das classificações tradicionais. Faraco, Castro e Tezza ${ }^{28}$ pontuam que esta disputa por uma classificação adequada ou correta do pensamento bakhtiniano dominou os debates da década de 1980, produzindo diversas imagens diferentes e parciais do pensador russo. Sobre este fenômeno, alegam: "se é conseqüência da forma como seus textos foram sendo divulgados, é também uma compreensível reação do mundo acadêmico. Diante do novo e do inusitado, trata-se logo de reduzi-lo ao conhecido e estabelecido." 29

Neste mesmo sentido, Faraco acrescenta a conjuntura político-econômica na qual a obra bakhtiniana foi recebida, numa clara referência à produção dos pesquisadores de Yale.

Lembramos, de início, que vários eslavistas estadunidenses, particularmente na década de 1980 (talvez ainda como efeito da Guerra Fria), e vários intelectuais russos, em especial depois do fim da URSS (talvez como efeito da ressaca pós-comunista), fizeram ingentes esforços para desvincular o Círculo de Bakhtin do marxismo. ${ }^{30}$

É válido ressaltar que a hipótese de Faraco não é original. Ao editarem ativamente textos do psicólogo russo Lev Vygotsky, contemporâneo de Bakhtin, os organizadores de seus livros foram criticados por terem censurado diversas passagens que indicavam a vinculação da teoria psicológica ao materialismo marxista, na introdução das obras nos Estados Unidos. Segundo os editores de A formação social da mente, "o leitor não deve esperar encontrar uma tradução literal de Vygotsky, mas, sim, uma tradução editada da qual omitimos as matérias aparentemente redundantes e à qual acrescentamos materiais que nos pareceram importantes no sentido de tornar mais claras as idéias de Vygotsky."31

Ao confrontarem a obra de Clark e Holquist e o enquadramento religioso conferido por esses autores a Bakhtin, Faraco e Tezza não estabelecem outra

\footnotetext{
${ }^{28}$ Faraco, Carlos Alberto; Tezza, Cristovão; Castro, Gilberto de. Apresentação. In.: (Orgs.). Diálogos com Bakhtin. 4. ed. Curitiba: UFPR, 2007.

${ }^{29}$ Id., p. 10

${ }^{30}$ Faraco, C. A. Linguagem e diálogo... p. 27.

${ }^{31}$ Cole, Michael; et al. Prefácio dos organizadores da obra. In.: Vygotsky, Lev Semenovich. A formação social da mente: o desenvolvimento dos processos psicológicos superiores. 6. ed. São Paulo: Martins Fontes, 1998, p. 14.
} 
classificação epistemológica no lugar. Antes, preferem apontar para o que entendem ser o caráter singular e único do pensamento deste autor, defendendo que não é possível vinculá-lo a qualquer corrente tradicional de pensamento sem prejuízo da compreensão de suas ideias.

Se não indicam uma vinculação positiva de Bakhtin, apontam, por outro lado, para as influências negativas, aquelas contra as quais o russo se insurgiu. Nesse aspecto, enfatizam sua crítica à construção teórica de Ferdinand Saussure que, criando a corrente estruturalista, privou a língua da fala e, consequentemente, de sua natureza enunciativa e subjetiva. Para os intelectuais da escola curitibana, Saussure desponta como o principal foco de confronto para Bakhtin.

Por esse prisma, a autoria - tão enfatizada pela visão ortodoxa russa de Clark e Holquist - deixa de ser o conceito principal da arquitetônica bakhtiniana. Em seu lugar, emerge o conceito que reintegra fala e língua, sujeito e mundo, vida e cultura: o diálogo, a dialogia. Em diferentes oportunidades, tanto Faraco ${ }^{32}$ quanto Tezza ${ }^{33}$ defenderam a proeminência do dialogismo sobre os demais conceitos bakhtinianos, que dele decorrem.

Se a autoria representa para os pensadores da Yale a reconstrução de uma teologia ou filosofia da religião em termos de uma filosofia da linguagem, para os pensadores da Federal do Paraná a dialogia serve como metáfora para o grande projeto bakhtiniano de pluralismo cultural, além de representar sua própria existência.

É relevante compreender que, embora o presente artigo tenha se focado nos primeiros anos da carreira de Bakhtin, sua tumultuada existência prosseguiu por vários anos. Em 1929, pouco antes da publicação de sua obra sobre Dostoievski, foi preso e condenado a um exílio de seis anos no Cazaquistão, pena acrescida da impossibilidade de lecionar em universidades durante certo período após o término do exílio.

Nas décadas de 1930, 1940 e 1950 permaneceu em completo ostracismo. Elaborou sua tese de doutorado sobre François Rabelais e a cultura popular do riso durante a Idade Média. No entanto, esta não foi aprovada. Ocupou alguns cargos como professor em instituições sem visibilidade até se aposentar em 1961. Pode-se dizer que a redescoberta de sua existência e de sua obra ocorreu na década de 1960. Em 1963 foi

\footnotetext{
${ }^{32}$ Faraco, C. A. Linguagem e diálogo...

${ }^{33}$ Tezza, Cristovão. Sobre O autor e o herói - um roteiro de leitura. In.: Faraco, Carlos Alberto; Tezza, Cristovão; Castro, Gilberto de (Orgs.). Diálogos com Bakhtin. 4. ed. Curitiba: UFPR, 2007.
} 
publicada a segunda edição de sua obra sobre Dostoievski, com algumas revisões (Problemas da poética de Dostoievski); seguida, dois anos depois, da publicação de sua tese sobre Rabelais (A cultura popular na Idade Média e no Renascimento: o contexto de François Rabelais).

Em 1969, pelas graves complicações de sua saúde, recebeu autorização para residir em Moscou, onde poderia obter tratamento adequado, permanecendo nesta cidade até sua morte em 1975.

À guisa de conclusão, retomam-se os questionamentos originais deste artigo: que fatores influenciaram tamanha disparidade na recepção da obra de Mikhail Bakhtin? Não sendo ainda possíveis declarações peremptórias ou conclusivas, parte-se para a apresentação de algumas hipóteses.

A primeira delas está ligada ao momento de recebimento dos textos. Se é corretor afirmar, como apontou Faraco, que o contexto estadunidense era marcado pela tensão da Guerra Fria e de suas consequências ideológicas de purificação contra o marxismo, também é verdade que o contexto brasileiro foi marcado pela ditadura militar e pelas manifestações de oposição ao regime, na busca pela sempre almejada liberdade de pensamento e de ação.

Soma-se à primeira hipótese uma segunda, ligada ao recebimento das obras. A primeira tradução de Bakhtin para o inglês ocorreu em 1968 e consistiu em sua tese, escrita na década de 1940, intitulada Rabelais and his world ${ }^{34}$. Já no Brasil, a primeira tradução de Bakhtin (ou de seu Círculo) ocorreu em 1979, sendo a obra Marxismo e filosofia da linguagem ${ }^{35}$, de 1929. Tal diversidade exemplifica bem a introdução desordenada dos trabalhos de Bakhtin no Ocidente. Nota-se que, enquanto a primeira obra versa sobre a cultura popular na Idade Média e no Renascimento, tocando diretamente no ponto da religiosidade, o segundo texto tem a preocupação de estabelecer uma teoria de análise da cultura, no geral, e da linguagem, em particular, a partir de fundamentos marxistas e não de teorias idealistas.

Por fim, apresenta-se a terceira hipótese que, ligada às anteriores, consiste no recebimento dos conceitos. Embora não se possa falar que determinados conceitos foram ignorados, é certo que muitos deles foram interpretados de formas bastante

\footnotetext{
${ }^{34}$ Silva, Adriana Pucci Penteado de Faria e. O, $5 \mathrm{~mm}$ : a nova edição brasileira de problemas da poética de Dostoiévski. Bakhtiniana, Rev. Estud. Discurso, São Paulo, v. 6, n. 1, Dec. 2011.

${ }^{35}$ Ornellas, Clara Ávila. Mikhail Bakhtin no Brasil: primeiras repercussões. Espéculo, Revista de estudios literarios, Madrid, n. 43, 2010.
} 
diversas, inclusive no tocante à importância. Resta claro que o campo conceitual apresentado por cada um dos comentadores - com a valorização da autoria, de um lado, e da dialogia, de outro - é visto à luz da biografia do russo e em conexão com os assumidos ou presumidos projetos dele.

Em um contexto de negação do marxismo e sob o impacto original da leitura bakhtiniana sobre uma cultura marcadamente religiosa, Clark e Holquist apegaram-se a um espectro filosófico de Bakhtin, vendo em seu conceito de autoria o cerne de seu edifício teórico e traçando uma clara ligação entre seu pensamento e a herança do Cristianismo Ortodoxo. A experiência brasileira, por outro lado, foi sensivelmente diferente. No contexto de um governo militarizado e tido como opressor das liberdades individuais, a obra marxista recebida mobilizou discussões sobre as estruturas sociais e sobre os traços ideológicos presentes em todas as manifestações simbólicas e culturais. A partir daí, Bakhtin foi recebido principalmente por suas ideias linguísticas, levando ao ápice das análises brasileiras o conceito de dialogia, tido como fundamento da arquitetônica bakhtiniana

\section{Referências}

AMORIM, Marilia. Para uma filosofia do ato: "válido e inserido no contexto". In.: Brait, Beth (Org.). Bakhtin, dialogismo e polifonia. São Paulo: Contexto, 2012.

BEZERRA, Paulo. Os passos perdidos de Bakhtin. Jornal de Resenhas, Folha de São Paulo. 13 ago 1998. Disponível em: <http://www1.folha.uol.com.br/fsp/resenha/ rs13089814.htm>. Acesso em: 9/11/2013.

BRAIT, Beth. Bakhtin e a natureza constitutivamente dialógica da linguagem. In.: Brait, Beth (Org.). Bakhtin, dialogismo e construção de sentido. 2. ed. rev. Campinas: Unicamp, 2005.

CLARK, Katerina; HOLQUIST, Michael. Mikhail Bakhtin. São Paulo: Perspectiva, 2008.

COLE, Michael; et al. Prefácio dos organizadores da obra. In.: Vygotsky, Lev Semenovich. A formação social da mente: o desenvolvimento dos processos psicológicos superiores. 6. ed. São Paulo: Martins Fontes, 1998. 
FARACO, Carlos Alberto. Linguagem \& diálogo: as ideias linguísticas do Círculo de Bakhtin. São Paulo: Parábola Editorial, 2009.

FARACO, Carlos Alberto; Tezza, Cristovão; Castro, Gilberto de. Apresentação. In.:

(Orgs.). Diálogos com Bakhtin. 4. ed. Curitiba: UFPR, 2007.

ORNELLAS, Clara Ávila. Mikhail Bakhtin no Brasil: primeiras repercussões. Espéculo, Revista de estudios literarios, Madrid, n. 43, 2010.

SCHNAIDERMAN, Boris. Bakhtin 40 graus: uma experiência brasileira. In.: Brait, Beth (Org.). Bakhtin, dialogismo e construção de sentido. 2. ed. rev. Campinas: Unicamp, 2005.

SCHNAIDERMAN, Boris. Bakhtin e o Ocidente: etapas de uma aproximação. In.: Clark, Katerina; Holquist, Michael. Mikhail Bakhtin. São Paulo: Perspectiva, 2008.

SILVA, Adriana Pucci Penteado de Faria e. O, $5 \mathrm{~mm}$ : a nova edição brasileira de problemas da poética de Dostoiévski. Bakhtiniana, Rev. Estud. Discurso, São Paulo, v. 6, n. 1, Dec. 2011.

TEZZA, Cristovão. A vida polifônica de Mikhail Bakhtin, de Katerina Clark e Michael Holquist, 1998. Disponível em: < http://www.cristovaotezza.com.br/textos/ resenhas/p_9805_cult.htm>. Acesso em: 9/11/2013.

TEZZA, Cristovão. Sobre O autor e o herói - um roteiro de leitura. In.: Faraco, Carlos Alberto; Tezza, Cristovão; Castro, Gilberto de (Orgs.). Diálogos com Bakhtin. 4. ed. Curitiba: UFPR, 2007.

TEZZA, Cristovão. A construção das vozes no romance. In.: Brait, Beth (Org.). Bakhtin: dialogismo e construção de sentido. 2. ed. rev. Campinas: Unicamp, 2005.

Recebido: 06/02/2014

Received: 02/06/2014

Aprovado: 19/07/2014

Approved: 07/19/2014 